\title{
La nueva novela histórica y la construcción de la feminidad en una novela de Gioconda Belli ${ }^{1}$
}

\section{(The New Historical Novel and the Construction of Femininity in a Novel by Gioconda Belli)}

\section{Gustavo Camacho Guzmán²}

Universidad Nacional, Costa Rica

\section{RESUMEN}

Se analiza El pergamino de la seducción, de Gioconda Belli, sobre Juana la Loca (1479-1555), la hija de los Reyes Católicos. Se estudian las construcciones de los personajes femeninos (Juana la Loca, Isabel la Católica y Lucía), y se pone de manifiesto que, si bien la novela efectúa una reivindicación del personaje femenino y de su figura frente al varón, en la construcción de los personajes de la novela subyacen contradicciones respecto de esta posición frente a la figura masculina.

\begin{abstract}
An analysis is presented on El pergamino de la seducción, by Gioconda Belli, about Juana de Castilla (1479-1555). The study refers to the construction of female characters (Juana de Castilla, Isabel La Católica, and Lucía). It is shown that although the novel attempts to revendicate female characters and the feminine figure as opposed to that of the male, there are underlying contradictions in their constructions regarding their position and the masculine figure.
\end{abstract}

1 Recibido: 5 de setiembre de 2017; aceptado: 2 de mayo de 2018. Una versión preliminar de este trabajo se presentó en el IV Coloquio Internacional sobre Diversidad Cultural y Estudios Regionales (agosto 2016), celebrado en la Universidad de Costa Rica, sede de Occidente.

2 Escuela de Literatura y Ciencias del Lenguaje. Correo electrónico: gustavo_a_72@homail.com

LETRAS 63 (2018), ISSN 1409-424X; EISSN 2215-4094 
Palabras clave: novela histórica, narrativa centroamericana, Gioconda Belli

Keywords: historical novel, Central American narrative, Gioconda Belli

En la narrativa centroamericana escrita por mujeres, es recurrente la creación de personajes que buscan ejercer un protagonismo subversor, si se lo compara con la concepción tradicional del personaje femenino. Algunas novelas cuentan con una serie de personajes, cuya representación no coincide con las ideas y concepciones que la tradición ha asignado al personaje femenino. Es el caso de obras de Malín D’Echevers (1896-1977), Argentina Díaz Lozano (1912-1919) y Gioconda Belli (1948) ${ }^{3}$.

Resulta interesante la posibilidad de reunir en una misma novela esta construcción del personaje femenino y el discurso propio de la llamada nueva novela histórica, modalidad que alcanzó auge durante la segunda mitad del siglo xx. Para Fernando Aínsa, el objetivo de tal modalidad narrativa consiste en «dar sentido y coherencia a la actualidad desde una visión crítica del pasado» ${ }^{4}$. Esta es la razón por la cual la novela histórica contemporánea desmitifica y toma distancia del discurso instaurado sobre el pasado. Esta misma idea es desarrollada por Lukasz Grützmacher, para quien la nueva novela histórica es propia de los finales de la década de 1970, aunque su producción se acentúe hacia 1992, a propósito del quinto centenario de la llegada de Colón a América.

Por su propia índole, la nueva novela histórica toma el pasado desde una visión crítica, incluso paródica, puesto que se vale de recursos discursivos como la ironía y el humor para desconstruir una concepción mítica sobre el pretérito. De esta manera, la nueva novela histórica critica el discurso oficial y construye una nueva versión del pasado, ya fuera en lo que la historia dice o ya en lo que esta deja de

3 Ejemplos de novelas de las autoras mencionadas con estas características son Metal noble (1966), Peregrinaje (1944) y El intenso calor de la luna (2014), respectivamente.

4 Fernando Aínsa, «La reescritura de la historia en la nueva narrativa latinoamericana», Cuadernos Americanos 4 (1991): 18. 
decir. Tal desapego del discurso objetivo y los acontecimientos tal cual sucedieron, une de forma significativa a la nueva novela histórica con los discursos del desencanto, de la estética de la posmodernidad ${ }^{5}$.

Esta construcción crítica del pasado está en El pergamino de la seducción (2005), de Gioconda Belli. La reelaboración literaria del pretérito se conjuga con la construcción de un personaje femenino, acallado y estigmatizado por el patriarcado, al que se le otorga una voz propia, lo cual hace de El pergamino de la seducción, además de novela histórica, un texto en el que se construye un discurso de reivindicación de Juana la Loca, o Juana de Castilla. En cuanto a este personaje, se detiene en describir sus relaciones con las estructuras de poder predominantes en la España del siglo XvI. Por ello, el texto presenta la personalidad rebelde de Juana para con las imposiciones de la cultura que le correspondió vivir, lo cual hizo que la reina sufriera la estigmatización y el encierro.

Otro aspecto es la forma como se organiza la narración, pues la historia de Juana de Castilla se encuentra intercalada en una segunda trama, mostrada en el siglo xx. En este segundo plano temporal, se desarrolla la historia de Lucía, adolescente huérfana que establece una relación con Manuel, profesor especialista en el Renacimiento español $\mathrm{y}$ descendiente de quienes cuidaron de Juana durante su encierro. Al mismo tiempo que se desarrolla una narración ficcional del pretérito, se presenta el proceso de crecimiento de una adolescente y su gradual tránsito a la vida adulta.

La vida de Juana de Castilla y su relación con Felipe el Hermoso se reconstruyen a partir del mismo discurso histórico enunciado por un hombre, conocedor de la historia y la vida de Juana: Manuel narra a Lucía los acontecimientos del pasado para dilucidar, desde la sensibilidad de una adolescente, cuáles fueron las posibles experiencias y sentimientos de Juana durante las diferentes etapas y circunstancias

5 Lukasz Grützmacher, «Las trampas del concepto "la nueva novela histórica” y de la retórica de la historia postoficial», Acta Poética 2 (2006): 141. DOI:https//doi.org/10.19130/iifl.ap.2006.1.193. 
que debió afrontar a lo largo de su vida ${ }^{6}$; es decir, Manuel desea conocer lo que no se encuentra en los textos históricos sobre Juana de Castilla, lo ocultado. Ello se debe a que Manuel está obsesionado con la figura de la reina Juana y desea reconstruir por medio de Lucía la interioridad de Juana la Loca: «Quiero que levantes con tu imaginación los escenarios que te describiré, que los veas y te veas en ellos, que te sientas como Juana por unas horas» ${ }^{7}$.

De esta manera, la relación amorosa entre Lucía y Manuel, surgida en función de la vida de Juana y Felipe el Hermoso, se desarrolla junto a los acontecimientos por él narrados. Esta identificación lleva a que las dos relaciones (entre Juana y Felipe, y entre Lucía y Manuel) acaban siendo una. Ello le permite a Wanda Delgado Rodríguez afirmar que esta conformación novelesca trata de una mujer interna, que se concreta mediante la voz y de la acción de otra mujer: Juana es recreada en la experiencia y en el sentir de Lucía ${ }^{8}$. Desde el inicio, se pone de manifiesto una notable conexión entre ambos personajes. Al respecto, Lucía afirma:

[...] Miré fija y largamente el rostro de Juana. El parecido conmigo era notorio y lo más curioso era que no se trataba de una similitud de rasgos, sino de algo menos preciso, quizás lo que en mi país llamaban «darse un aire» a tal o cual persona (68).

Esta similitud también es palpable entre Manuel y Felipe: el primero enamora a Lucía al punto en que acaban siendo idénticos a los príncipes de Flandes y Castilla; por tanto, llegan a confundirse ambos amoríos; esto coincide con la iniciación sexual de Lucía; es

6 Juana de Castilla fue hija de los Reyes Católicos. Fue casada, por razones de Estado, con Felipe el Hermoso, príncipe de Flandes. Véase Lucinda Gil Parra. (2012) Juana la Loca. 10 de junio, 2016. Disponible en: <http://mayores.uji.es/datos/2011/apuntes/fin_ciclo_2012/Juana.pdf>.

7 Gioconda Belli, El pergamino de la seducción (Barcelona: Seix-Barral, 2007) 11; en adelante se indican entre paréntesis los números de página.

8 Wanda Delgado Rodríguez, «La mujer habitada y El pergamino de la seducción. Dos propuestas del ser femenino en Gioconda Belli», El Amauta 8-9 (s.p.). De este modo, la narración se desarrolla como si fuera un péndulo, que trata de manera alternada la historia y la vida de ambas mujeres, puesto que Juana toma la voz de Lucía para expresarse. 
decir, con el crecimiento de este personaje ${ }^{9}$. Por ello, la novela no trata solamente sobre el pasado histórico; también sobre el aprendizaje de una adolescente y el tránsito de la niñez a la vida adulta:

[...] Susurré gimiendo que no alcanzaba, que no podía, pero Felipe o Manuel, no sé quién era ni importaba ya, me clavó los brazos abiertos en las almohadas y sobre mis gritos y llanto empujó su sexo como si taladrara mis entrañas en busca de agua y al fin sentí el desgarramiento y la penetración honda [...] (108, destacado propio).

Con respecto a la reina Juana, este se caracteriza por vivir un estado de opresión desde su época de niñez. La corte de los Reyes Católicos, por las circunstancias de la reconquista y de la lucha contra la invasión musulmana, es itinerante en función de los intereses y las necesidades militares. Juana pasa su niñez en medio del castigo y la sujeción a una conducta mesurada: «Si río a carcajadas, me dan de palos porque la experiencia enseña que el castigo físico es medicina para la locura de las niñas y que el dolor es saludable para la disciplina de nuestros cuerpos» (51). Para la cultura patriarcal, a la mujer se la considera un ser falto de cordura al que es necesario disciplinar a través del castigo físico. Esto explica la situación de Juana ya viuda: por considerar que ha perdido el juicio, se la encierra y se la castiga hasta su muerte.

A pesar de vivir dentro de una sociedad conservadora y patriarcal, el personaje se resiste a esa vida de austeridad y de castigo; no se somete a las normas de comportamiento promovidas por la sociedad en que vive. Ello se manifiesta, de forma explícita en el plano sexual, puesto que Juana vive su sexualidad a su voluntad, y en consecuencia, se rebela en contra de la proverbial austeridad de los castellanos, una vez casada con Felipe. Sin embargo, el desapego de las reglas que el patriarcado impone a Juana en el ámbito corporal alcanza otros

9 La primera relación sexual entre Lucía y Manuel coincide con el momento en el que este narra a Lucía la noche de bodas de Juana y Felipe. A partir de este acontecimiento, la relación entre Lucía y Manuel va a coincidir, en algunos puntos, con la de los dos príncipes. 
aspectos de la vida de la reina, sobre todo en cuanto al plano espiritual: en Flandes, adopta las costumbres de la corte flamenca, por lo que abandona las maneras propias de Castilla y descuida los deberes religiosos, tan importantes para los castellanos. Ambos aspectos: la vivencia plena de la sexualidad y la desatención a los ritos piadosos, manifiestan una conducta renacentista en el pensamiento de Juana, propio de su época, puesto que, durante el Renacimiento, el interés se halla en el ser humano, y no en lo divino. De este modo, en el texto se plantea una pugna implícita entre dos modelos de pensamiento y el tránsito de la mentalidad medieval a una de carácter renacentista. Con ello, además, se propone una oposición entre castellanos y flamencos, pues si para los primeros son de capital importancia el aspecto espiritual, las prácticas piadosas y la austeridad (el teocentrismo de la Edad Media), para los segundos son más importantes el aspecto material, el goce corporal y la disipación (el antropocentrismo del Renacimiento):

La felicidad de mi carne cada noche me incitaba a rebelarme contra los resabios de la rigidez castellana que prevalecían en el séquito leal a mi madre [...]. Me recriminaba mi confesor Diego Ramírez de Villaescusa, quien también se quejaba de mi falta de interés por las devociones religiosas. Me hacía perder la paciencia [...] con las peroratas en que acusaba a mis súbditos de preocuparse más por el buen beber que por la virtud, como si comer y beber fueran placeres prohibidos o pecaminosos ${ }^{10}$.

En cuanto a la sexualidad, la libertad de la que goza el personaje rebasa el matrimonio, puesto que la narración sugiere un posible lesbianismo, con las mujeres que se encargan de servir a la reina:

Varias de ellas [de sus sirvientas] eran tan hermosas que verlas desnudas y sentir sus pechos sobre mi cabeza [...] excitaba todos los

10 Belli, 122. Son numerosos los pasajes en que se describe a Juana como una mujer con libertades inadmisibles para la convención patriarcal, aunque sea su esposo quien aliente tales conductas. Un ejemplo de ello es la afición de Felipe por que su esposa muestre los pechos ante la corte para observar las reacciones de los nobles. Véase Belli, 129. 
diablos de la tentación. Ellas no se conformaban con los aceites que me echaban en el cuerpo, ni con el azúcar con que me frotaban para eliminar las asperezas, sino que me lo quitaban de encima lamiéndolo con sus lenguas (259).

Esta decisión de disfrutar sin reserva de la sensualidad es reprimida y censurada por los demás personajes, en particular por Felipe, quien elabora un informe de las acciones de su esposa para enterar a los Reyes Católicos, y con ello, ofrecer pruebas de la locura de Juana. Afirmar la pérdida del juicio de Juana sería una estrategia política para evitar su posible coronación como reina de España. Esto es fundamental para justificar el maltrato y el encierro a la que fue sometida: el patriarcado no permite ni acepta el comportamiento de Juana, en cuanto no se ajusta a las convenciones. Manuel, especialista en la vida de Juana, expresa esta idea de la siguiente manera: «Para sus coetáneos, descalificarla era más fácil que comprenderla» (261), y tal desacreditación de la heredera de la corona de España traía consigo una ventaja política para sus adversarios.

El comportamiento rebelde de Juana se extiende más allá del descuido de las prácticas piadosas, tan importantes para sus compatriotas, y de la vivencia plena de la sexualidad. Su conducta se extiende a la relación con su esposo, y en ocasiones en la relación con su padre, Fernando el Católico, pues Juana considera que la mujer no tiene por qué doblegarse al varón (142). Esta idea acaba reafirmada durante el viaje de Juana y Felipe a España, a propósito de una cabalgata hacia la catedral de Toledo: «Que [Felipe el Hermoso y Fernando de Aragón] hubiesen alcanzado la catedral sin mí era un desplante que no pasamos por alto ni mi madre ni yo [...] Les disculpé la fanfarronería, su necesidad masculina de marcar territorio» (182).

El reclamo de igualdad ante a su esposo y a su padre resulta contradicha en cuanto Juana se ve obligada a enfrentarse a una situación crítica. Muerto su marido, pierde el apoyo de la corte española. Esta circunstancia la aprovechan la corte y sus adversarios para desautorizarla y hacerla ver, 
por causa del alegato de locura, incapaz de encargarse del gobierno. Para resolver la sucesión al trono de España, Juana decide llamar a Fernando el Católico. Debido a los rumores y comentarios de la corte, desea mostrarse fría y lúcida mentalmente para encontrarse con su padre; sin embargo, Juana delega el poder y la autoridad que le estaban reservados como heredera legítima. Con ello, le otorga a Fernando un carácter casi divino:

[...] Doblé las piernas y caí de hinojos a su lado. Lo abracé poseída por una abrumadora sensación de amor y sosiego. Allí, mientras me estrechaba entre sus brazos, decidí mis contradicciones. Me vino a la mente la frase del padre nuestro «hágase tu voluntad así en la tierra como en el cielo». Que se hiciera la voluntad de mi padre [...] (336).

De esta manera, el modelo de feminidad que la novela había construido con Juana de Castilla, como mujer que no se ajustaba a los cánones del patriarcado, acaba subvertido frente a la figura del padre. En suma, acepta la superioridad de Fernando el Católico, y por extensión, del hombre en cuanto a los asuntos que ella no puede solucionar.

Aunque el discurso oficial sobre la vida de Juana de Castilla promoviera el rumor de la locura, la narración desarrolla una idea opuesta: la reina no habría perdido el juicio, pues su comportamiento y su falta de cordura obedecían a un mecanismo de defensa frente a la represión de la que fue objeto. En varias ocasiones, la corte designó a algunas personas que indagaran sobre su estado mental; de este examen, el almirante de Castilla concluyó que era una mentira el afirmar la locura de la reina (307). Esta ambigüedad entre la locura y la lucidez basta para que Juana fuese un personaje temible, una figura que rechaza el patriarcado, y por ello, se crea necesario mantener en el aislamiento y en la soledad una vez muerto Felipe el Hermoso ${ }^{11}$. La

11 En la «Nota final», Gioconda Belli explica que, más que una locura, lo que la reina Juana pudo haber sufrido fue una depresión, una tendencia maniaco-depresiva o de bipolaridad, explicables por las circunstancias y la represión a la que fue sometida, pues las crisis corresponden a momentos en que se halla forzada a aceptar decisiones difíciles; al respecto, véase Belli, 403-404. A propósito de la atracción y repulsión que causa la reina Juana en los cortesanos, véase Belli, 335. 
locura de Juana se atribuye a una forma de conducta incomprensible e inaceptable para la sociedad patriarcal: resulta más sencillo rechazar a la mujer fuerte, incomprensible para el patriarcado, para encubrir el temor del hombre frente a la fuerza de la mujer: «iMalhadada suerte la nuestra de mujeres fuertes y temidas de los hombres! ¡Tenían que encerrarnos, humillarnos, pegarnos, para olvidar el temor que les inspirábamos y sentirse reyes!» (365).

Lucía y Manuel hallan un cofre que perteneció a Juana, donde encuentran el manuscrito en que ella expresa su sentir sobre su condición de mujer fuerte, reprimida y rechazada por la inquietud e inestabilidad que ello genera en el poder masculino. La finalidad de este manuscrito concuerda con el objetivo de la nueva novela histórica de dar voz a los que el discurso dominante ha acallado, y con ello plantear una perspectiva distinta de la tradicional sobre los hechos del pretérito. En este manuscrito, se afirma rebelar en contra del sistema que la oprime y condena. Para Juana, quienes se encargan de vigilarla en su encierro proyectan en ella las fantasías que les provoca una mujer incomprendida: «Porque no me entienden piensan que Satanás me habita, piensan que duermo con él, que así aplaco las pasiones legendarias de mi cuerpo, acostumbrado a la carnalidad del amor» (391). Es esta misma incomprensión la que provoca que Juana ponga en entredicho la idea de su propia locura, en tanto no es explicable que la corte guarde tantas precauciones para mantener bajo control a una persona que ha perdido el juicio (392). Por ello, la liberación de Juana se encuentra, solamente, en la muerte: solo con la muerte; con ella será libre de un sistema que, por no poder subyugarla, la encierra y la rechaza.

Un modelo de feminidad no cuestionado por la sociedad consiste en el de la reina Isabel, la madre de Juana. La Reina Católica es un personaje con libertad de decisión, y al cual no se le desautoriza ni desacredita, en tanto es un personaje que acepta las imposiciones del modelo patriarcal de mujer. Su genio es incuestionable y decidido: «[...] el gesto más revelador de su genio es la manera en que, a día 
siguiente de la muerte de Enrique [hermano de Isabel], quien murió sin hacer testamento, se hizo coronar reina de facto [...]» (59). A estas características se une su frialdad de temperamento; Juana describe a su madre como una «virgen de cera, remota y carente de fuego», a la que le recrimina su desapego por sus propios hijos, puesto que Isabel concede mayor importancia a los intereses del Estado y del gobierno, por encima de su propia familia (222-223). Por ello, el principal reclamo de Juana para con su madre es el no haberle permitido, una vez viuda, regresar a Bruselas para reunirse con sus hijos. Esta decisión de Isabel le permite a Juana creer que el único interés de la reina Católica es la conservación de la corona y del poder, aunque para ello se deban sacrificar las relaciones familiares y de parentesco.

Empero, esta situación muestra una contradicción en la reina Isabel: ella no duda en separar a Juana de sus hijos; sin embargo, para Isabel es difícil separarse de Juana cuando esta iba a embarcarse hacia Flandes para efectuar un matrimonio por conveniencia con Felipe el Hermoso, y así proteger los intereses de la corona de España. Isabel expresa, poco antes de la partida de su hija:

Ya verás cuán duro es, Juana, desprenderse de los hijos. Si en la vida cotidiana, mientras crecéis, uno os mira y apenas comprende que hayáis surgido de la propia entraña, basta un peligro o una despedida para que el cuerpo de una se rebele y ansíe la sangre correr en pos de las venas que alguna vez alimentó (84).

Los dos modelos de mujer que el texto presenta como parte del pasado histórico ofrecen una diferencia fundamental: el sometimiento a las reglas del patriarcado permite que el poder y la autoridad de Isabel la Católica sean respetados y temidos, mientras que la rebeldía a tal sistema implica el rechazo, la incomprensión y el estigma de la locura, por ser una conducta incomprensible para la sociedad patriarcal. Ya viuda, Juana acaba encerrada y vigilada hasta el día de su muerte, resulta incomprendida por la sociedad, al punto de satanizar su diferencia por medio de la superstición. 
El tercer modelo de mujer que la novela plantea es el de una adolescente que vive en la segunda mitad del siglo xx. Lucía es una huérfana de la que se narra su crecimiento; es un personaje que descubre el pasado de Juana y se inicia en la sexualidad con Manuel. La relación entre ellos es análoga a la que existió entre Juana y Felipe, al punto que ambas se llegan a confundir en la mente de Lucía:

No sabía dónde terminaba él y empezaba Felipe; ni si cuando estaba con él era Juana la que amaba a su marido a través mío, o éramos Manuel y yo quienes nos acariciamos. Nuestra historia no existía fuera de Juana y Felipe (139).

Esta confusión se da según dos aspectos: el discurso en que Manuel envuelve a Lucía en la historia de Juana y la utilización del disfraz. Una de las primeras condiciones que Manuel impone para reconstruir por medio de Lucía la interioridad de Juana es que ella utilice un vestido propio del siglo XvI. De este modo, el disfraz implica para Lucía la adopción plena de su papel como Juana de Castilla: «Una vez vestida tenía que admitir que Manuel no andaba del todo equivocado. Algo me sucedía. Podía separarme de mi ser cotidiano, imaginarme lejos de allí» (217). Esta es la circunstancia en que se recrea la voz y la vida de Juana.

La relación con Manuel pasa de una situación cordial en que, inicialmente, ella va a ayudarlo a conocer lo no contado sobre Juana, a una relación sentimental. Como consecuencia de ello, Lucía resulta embarazada de una niña. Esta circunstancia suscita que Lucía desee huir del colegio de religiosas en el que estudia. Como consecuencia de este embarazo, Manuel toma la responsabilidad y asume el cuidado de ella, hasta el momento en que él muere en el incendio de la casa que habitaba ${ }^{12}$. Este hecho repentino deja a Lucía en libertad; decide

12 La casa en que habitaban Manuel y Águeda, la madre de este, guardaba obras de arte y objetos valiosos, del siglo xvi, y fue construida por quienes se encargaban de cuidado de Juana en el encierro. El incendio de tal edificio queda registrado en la prensa como un accidente en el que se pierden obras de arte invaluables. Véase Belli, El pergamino de la seducción: 399. 
abandonar España para que su hija nazca en Nueva York, donde la espera una amiga de su difunta madre, y a través de la niña, reivindicar la memoria de Juana (401-402).

\section{Conclusiones}

Por estar ante una novela histórica, El pergamino de la seducción reconstruye una serie de hechos del pasado a partir de la ficción literaria; y más aun, como discurso novelesco, cuestiona y observa tales hechos desde una perspectiva crítica. Por las características descritas, se asocia a la corriente de la nueva novela histórica, al reescribir el pasado y ofrecer una voz silenciada por el discurso dominante. La novela presenta un aspecto llamativo, en tanto la restitución de tal voz se lleva a cabo desde la perspectiva de una mujer: la narración otorga voz a un ser marginado y oprimido por el sistema patriarcal. No es extraño que el texto plantee una construcción de la feminidad, un discurso propiamente femenino dentro de una novela de corte histórico.

Este modelo femenino no elude contradicciones: la libertad de Juana de Castilla acaba subordinada a la figura del padre; ello se debe a que Juana ve en Fernando el Católico a alguien superior a ella, a esto se une la delegación de la autoridad, lo cual resulta en el endiosamiento. Este hecho no ocurre ante a su esposo: ante Felipe, Juana adopta una actitud fuerte, puesto que no se subordina a él. Un ejemplo del desapego frente a la autoridad de su esposo consiste en la defensa de las prostitutas que Felipe hizo clandestinamente abordar en el barco en que la pareja haría su viaje a España. Al proponer, en una tormenta, que se arrojara a estas mujeres al mar para evitar el naufragio, puesto que este se entiende como un castigo divino, Juana responde: «No echarán a una sola de esas mujeres por la borda a menos que las acompañen quienes las trajeron al barco para desgracia nuestra, empezando por el rey [Felipe], mi señor, a quien sin duda debemos esta disposición» (277). 
Por su parte, Lucía ejerce su libertad después de la muerte de Manuel. Antes de ese acontecimiento, Lucía cuenta con libertades ajenas a las demás adolescentes ${ }^{13}$, pero su mismo embarazo la lleva a depender de su pareja, razón por la cual sufre una suerte de encierro cada vez que sale del colegio para pasar un fin de semana en casa de Manuel (161). Por ello, la libertad que ejercen los personajes femeninos de la novela es relativa, en el caso de Lucía, se halla subordinada a la figura y a la voluntad del personaje masculino. Esta condición solo se resuelve con la muerte de uno de los dos: Juana encuentra su liberación en su propia muerte, mientras que Lucía puede decidir su futuro por sí misma después de la muerte de Manuel.

En cuanto a Juana, su condición puede considerarse como una consecuencia de la sujeción que, en mayor o menor medida, la novela histórica posee respecto de los referentes. La fidelidad al referente histórico impone cierto tratamiento de los hechos, aunque la novela permita, por sus propias características, elaborar una ficción sobre ellos, y con ello, mencionar los aspectos del pretérito que el discurso histórico ha omitido ${ }^{14}$. En la relación entre la novela histórica y la novela escrita por mujeres, la reivindicación de las voces acalladas por el discurso histórico, labor propia de la nueva novela histórica, sirve en la presentación de una voz femenina, que ha sido atrayente y a la vez rechazada por el estigma de la locura. Juana no estuvo loca: su conducta fue la reacción en contra de la opresión a la que fue sometida.

13 Lucía es un personaje que se encuentra interno en un colegio de religiosas, y por su amistad con Manuel y con Águeda, pariente de este, logra contar con libertades que no son posibles para las demás internas, tales como establecer una relación sentimental con él, que es un hombre mucho mayor que ella.

14 Un estudio esclarecedor al respecto es el de Robin Lefere, La novela histórica: (re)definición, caracterización, tipología (Madrid: Visor Libros, 2013). 